IEEE VPPC Vehicle Power and Propulsion Conference, Coimbra Portugal, pp.1-5, Oct. 2014.

http://ieeexplore.ieee.org/xpls/abs all.jsp?arnumber=7007133

ISBN: 978-1-4799-6783-4

DOI: 10.1109/VPPC.2014.7007133

This material is posted here with permission of the IEEE. Such permission of the IEEE does not in any way imply IEEE endorsement of any of Group of Energy and Power Electronics, University of Minho, products or services. Internal or personal use of this material is permitted. However, permission to reprint/republish this material for advertising or promotional purposes or for creating new collective works for resale or redistribution must be obtained from the IEEE by writing to pubs-permissions@ieee.org. By choosing to view this document, you agree to all provisions of the copyright laws protecting it.

(C) 2014 IEEE 


\title{
Smart Charging Management for Electric Vehicle Battery Chargers
}

\author{
Vítor Monteiro, J. G. Pinto, Bruno Exposto, João C. Ferreira, João L. Afonso \\ ALGORITMI Research Centre - University of Minho \\ Guimarães, Portugal \\ \{vitor.monteiro | gabriel.pinto | bruno.exposto | joao.ferreira | joao.1.afonso\}@algoritmi.uminho.pt
}

\begin{abstract}
This paper proposes a smart battery charging strategy for Electric Vehicles (EVs) targeting the future smart homes. The proposed strategy consists in regulate the EV battery charging current in function of the total home current, aiming to prevent overcurrent trips in the main switch breaker. Computational and experimental results were obtained under real-time conditions to validate the proposed strategy. For such purpose was adapted a bidirectional EV battery charger prototype to operate in accordance with the aforementioned strategy. The proposed strategy was validated through experimental results obtained both in steady and transient states. The results show the correct operation of the EV battery charger even under heavy load variations.
\end{abstract}

Keywords-Electric Vehicle, Smart Battery Charger, Smart Grids, Smart Homes, Smart Charging Management

\section{INTRODUCTION}

With the promising change in the transport paradigm, several models of Electric Vehicles (EVs) are already available in the market. As example, for the United States it is predictable that the EVs will represent $64 \%$ of the light vehicles sales and $24 \%$ of the light vehicle fleet until 2030 [1]. Consequently, the interest of the scientific community in the development of technology related with electric mobility has been reflected in several publications. As example, in [2] is presented an overview about the state-of-the-art of EVs, hybrid EVs, and Fuel Cell Vehicles, and in [3] are presented the main architectures and modeling for energy management of these vehicles. This new paradigm of transport represents an asset to an effective reduction of greenhouse gases emissions [4]. Moreover, taking into account the energy resource constraints, the EVs can also be integrated in the power grid in conjunction with renewable energy [5][6].

The main purpose of the EV battery charging systems is charge the batteries (Grid-to-Vehicle, G2V). Nevertheless, they can also be designed to provide several additional features to the power grid, aiming to operate as distributed energy source and as smart load. Some of these features are related with deliver back to the power grid part of the energy stored in the vehicle battery (Vehicle-to-Grid) [7][8], operation as an active element in the power grid aiming produce reactive power to correct the power factor [9], and operation as isolated voltage source [10]. Despite the positive benefits of these features, the massive proliferation of EVs cannot be neglected, otherwise they can overload the power grids, because they were not conceived to support the massive proliferation of this new load [11]. The integration and consequent impact of EVs in the power grids is discussed in several papers in the literature
[12][13], where, for instance, can be found studies for China [14] or Canada [15].

Besides the controlled integration of EVs in the power grids, the power quality is also an important issue that must be contemplated in the EV battery charging system [16]. Therefore, the ac current of the EV battery charging system should be sinusoidal and in phase with the power grid voltage, aiming to regulate the power factor [17]. The combination of these subjects shows that the electric mobility is one of the main topics in the future smart grids [18]. There are several projects related with smart grids around the world, including the possibility of the de distribution in power grids [19]. In parallel with the growth of smart grids, will arise the smart home concept with efficient energy management systems [20][21]. In this context, it will be required smart EV battery chargers to perform the battery charging process according with the home energy management.

Taking this sequence of ideas, this paper proposes the use of an EV battery charger that can adapt its current in function of the other loads current in the home. This functionality aims to prevent overcurrent trips of the main switch breaker. Fig. 1 shows a block diagram that represents this concept, where $i_{G}$ represents the total current in the home, $i_{L D}$ the current of the loads, and $i_{E V}$ the EV charging current. According with the proposed strategy, the EV charging current $\left(i_{E V}\right)$ is function of the loads current $\left(i_{L D}\right)$, aiming to maintain the total home current $\left(i_{G}\right)$ controlled, and avoiding trips in the main switch breaker. For such purpose, as shown in Fig. 1, the home loads current is measured in the electrical switchboard and the data is

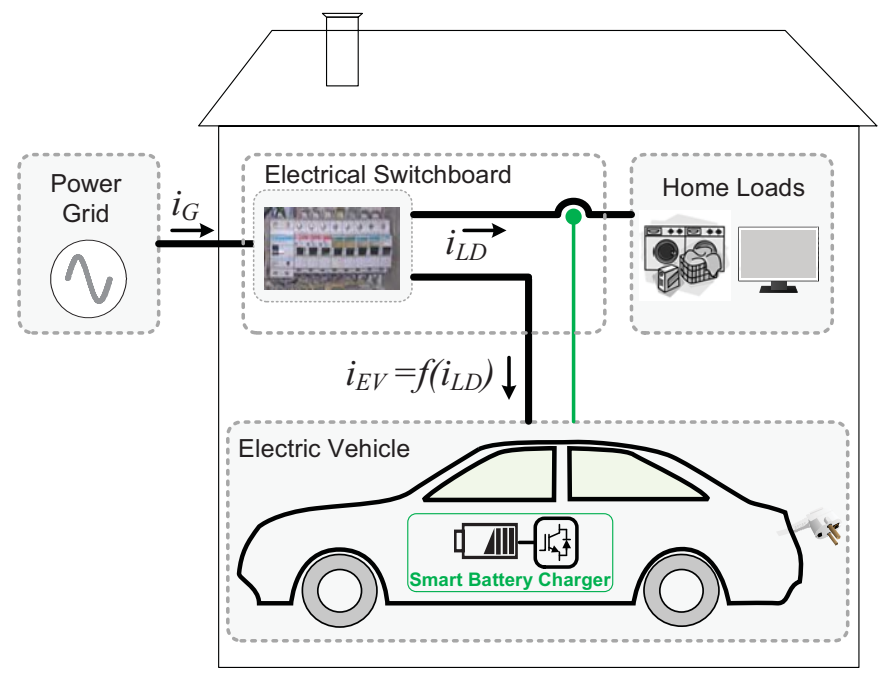

Fig. 1. Integration of an Electric Vehicle with a smart battery charger in a home. 
send to the EV. This concept will be further discussed in order to complement this analysis.

Besides the introduction, the rest of this paper is organized as follows. In section II is presented the system description and its relation with literature. In section III is presented the digital control implementation of the control algorithms for the EV battery charging system. In section IV are presented some experimental results that show the benefits of the smart charging management for EVs battery chargers presented in this paper. Finally, in section $\mathrm{V}$ are presented the main conclusions obtained in the scope of this paper.

\section{SYSTEM DESCRIPTION}

As is presented in Fig. 1, the system is composed by the EV battery charger, the home electrical switchboard, and the home loads. The EV battery charger uses the data from the loads current sensor to use it to adjust its own instantaneous current in accordance with those values. In order to implement this smart charging strategy, it is established that the maximum power available in the home is the power defined by the signed contract with the electricity service provider. To guarantee that the contracted power is not exceeded, the service provider installs a circuit breaker rated to the nominal current. In this situation, the maximum current allowed (the current to charge the EV battery plus the loads current) is established by the main circuit breaker installed in the home electrical switchboard.

In a typical situation, the EV is plugged in a home socket to perform the battery charging process without any concern about the contracted power for the home. In order to obtain reliable data about an EV battery charging process it was monitored the EV Renault Fluence charging process [22]. This monitoring was performed at University of Minho (Portugal) under secure and controlled conditions and with an appropriated electrical installation. To obtain the results was used a FLUKE 435 Power Quality Analyzer, programmed to register every 1 minute the rms value of the power grid voltage and current. The EV battery charging process was monitored several times in different conditions, for instance, performing the battery charging process after a full discharge and with different ambient temperatures. Fig. 2 shows the rms values of the current and the power grid voltage during a typical monitoring, e.g. when the batteries are initially full discharged. As shown in this figure, the current rms value is maintained constant and equal to $10 \mathrm{~A}$ almost all the time. It is also important to refer that the power factor was maintained almost unitary during all the EV battery charging process and the current was almost sinusoidal, with a percentage Total Harmonic Distortion (THD\% ) about 5\%.

As aforementioned, the main idea behind the proposed EV battery charging strategy is to adjust the charging current aiming to not exceed the contracted power. It must be referred, that this strategy influences the time required to complete the full EV battery charging. Nevertheless, this is the price to pay to ensure that the home maximum current (fixed by the contracted power) is never exceeded and the switch breaker is not tripped. It is also important to note that if the circuit breaker trips, then the charging process stops and the charging time will

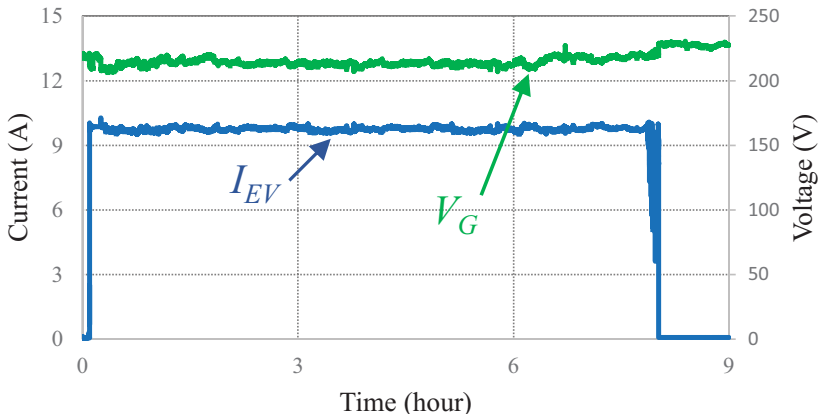

Fig. 2. Monitoring of the Renault Fluence battery charging process: Grid voltage $\left(v_{G}\right)$ and EV battery charger current $\left(i_{E V}\right)$.

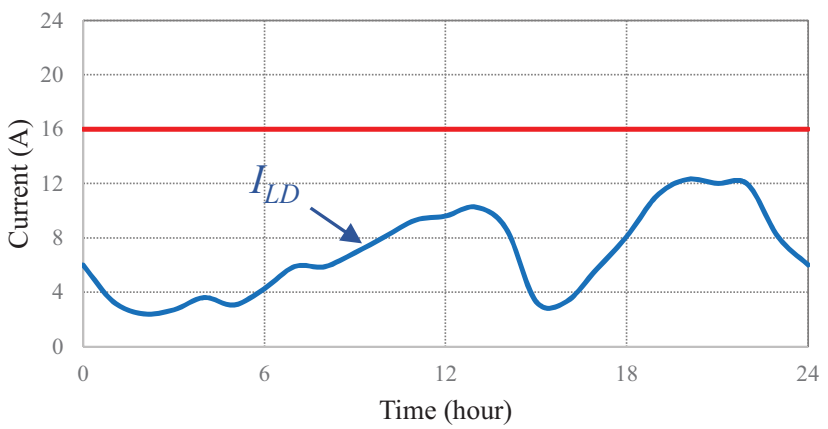

Fig. 3. Typical daily load current $\left(i_{L D}\right)$ profile in a home without the Electric Vehicle battery charging process.

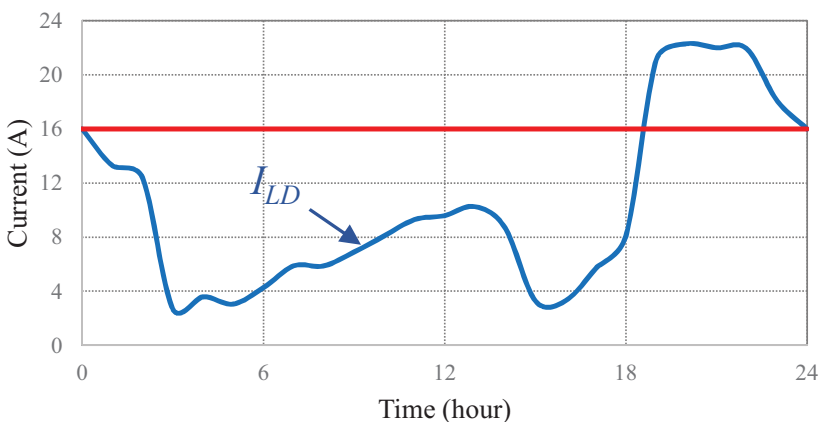

Fig. 4. Typical daily load current $\left(i_{L D}\right)$ profile in a home considering the Electric Vehicle battery charging process without control.

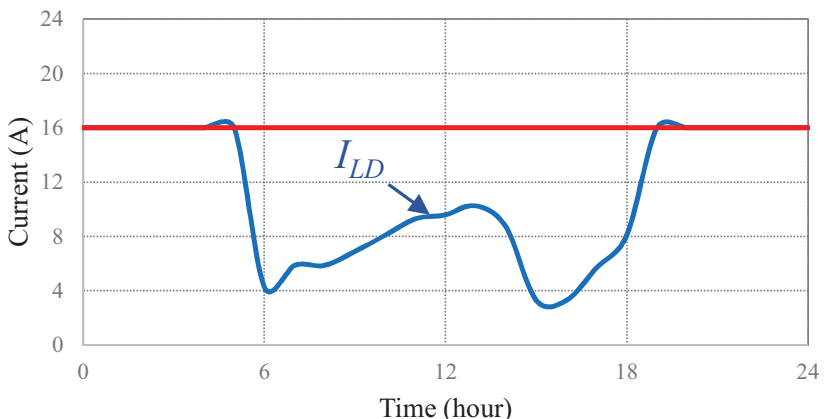

Fig. 5. Typical daily load current $\left(i_{L D}\right)$ profile in a home considering the Electric Vehicle battery charging process with the proposed control strategy.

be greater than in the case of reducing the charging current. Fig. 3 shows a typical daily load profile, where is presented the total home rms current $\left(i_{G}\right)$ and the maximum rms current for the home. In this case, it was assumed that the maximum current to prevent the switch trip is $16 \mathrm{~A}$, once is the most typically value for homes in low voltage (nominal phase-neutral voltage of $230 \mathrm{~V}$ ). As it can be seen in Fig. 3, the 
peak current occurs after seventeen hours. Considering this daily load profile and taking into account that private vehicles are parked at home between $7 \mathrm{pm}$ and $8 \mathrm{am}$, if the EV battery charging process is performed without any control, then the home main circuit breaker (rated to $16 \mathrm{~A}$ ) probably will trip. This situation is illustrated in Fig. 4, where the EV starts the battery charging process at $7 \mathrm{pm}$ and finishes the process at $3 \mathrm{am}$. As shown, for this situation, the maximum current (16 A) was exceeded between the $7 \mathrm{pm}$ and $0 \mathrm{am}$. On the other hand, considering a smart EV battery charging process, the home current is maintained below the circuit breaker rate and the trips are avoided. This situation is illustrated in Fig. 5. As shown, for this situation, the total home current was maintained constant during 10 hours, between $7 \mathrm{pm}$ and $5 \mathrm{am}$. In this case was required more time than the expected (according to the time specified by the manufacturer) to perform the full EV battery charging process. However, the switch breaker never trips during the EV battery charging process. It is important to note that the overcurrent situation (switch breaker trips) can occur even with dedicated EV home installation, once it is not possible predict the loads connected at the home electrical installation. Although these results portray a specific case, it is quite representative of the EV battery charging at home.

\section{DigITAL CONTROL IMPLEMENTATION}

Aiming to evaluate the proposed strategy it was adapted a bidirectional EV battery charger prototype to operate in accordance with the aforementioned strategy. The EV battery charger prototype that was used is composed by two power converters: one ac-dc front-end power converter; and one dc-dc non-isolated power converter. These converters are connected through the dc-link.

The ac-dc converter is synchronized with the power grid fundamental voltage through a single-phase Phase-Locked Loop (PLL) described in [23]. From this PLL is obtained a sinusoidal signal $(p l l)$ that corresponds to the fundamental component of the power grid voltage. The block diagram of this PLL is presented in Fig. 6. As aforementioned, the total home loads current is the variable that must be measured in order to implement the proposed strategy. In the scope of this paper the instantaneous value of the home loads current is measured using a current sensor and the values are acquired by the EV battery charger, where is calculated the rms value, according with:

$$
I_{L D}(t)=\sqrt{\frac{1}{T} \int_{0}^{T} i_{L D}^{2}(t) d t}
$$

The discrete implementation that allows calculate the rms value is obtained according with:

$$
I_{L D}[k]=\sqrt{\frac{1}{N} \sum_{k=1}^{k=N} i_{L D}{ }^{2}[k],}
$$

where, $N$ is the number of samples used in each cycle of the power grid voltage (in this case, using a sampling frequency of $40 \mathrm{khz}, N=800$ ). This equation allows calculate the rms value during one cycle $(50 \mathrm{~Hz})$. With the rms value of the home

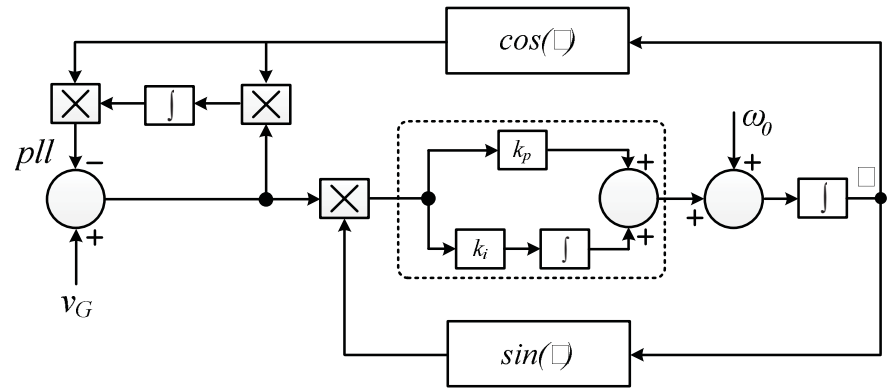

Fig. 6. Single-phase Phase Locked Loop that was used.

loads current and knowing the maximum current allowed by the main switch breaker installed in the electrical switchboard, it is determined the maximum rms current for the EV battery charging system, defined by:

$$
I_{E V}[k]=I_{G M A X}[k]-I_{L D}[k] .
$$

This rms current is the maximum reference to the ac-dc full-bridge converter, and it will determine the battery charging current, controlled by the dc-dc power converter. The rms current is expressed in function of the power reference used to regulate the dc-link voltage using a PI controller $\left(P_{D C}{ }^{*}\right)$, the current and voltage in the batteries $\left(I_{B A T}\right.$ and $\left.V_{B A T}\right)$, and the power grid voltage $\left(V_{G}\right)$, according with:

$$
I_{E V}[k]=\frac{P_{D C}{ }^{*}[k]+I_{B A T}[k] V_{B A T}[k]}{V_{G}[k]} .
$$

Rewritten (4) and putting in evidence the battery charging current is obtained:

$$
I_{B A T}[k]=\frac{V_{G}[k] I_{E V}[k]-P_{D C}{ }^{*}[k]}{V_{B A T}[k]} .
$$

This equation provides the constant current reference for the batteries charging process, where the current limit imposed by the rms current $\left(I_{E V}\right)$ of the ac-dc converter. The battery charging process is performed by the dc-dc converter, in which the current is controlled through a PI controller. The batteries are charged with constant current, but the reference value can change along the process, e.g. the batteries can be charged with constant current of $5 \mathrm{~A}$ during 30 minutes and then change the current value for $7 \mathrm{~A}$ during 10 minutes.

From (4), which provides the rms value of the ac-dc front-end converter, it can be calculated the instantaneous current for this converter using:

$$
i_{E V}{ }^{*}[k]=\frac{P_{D C}{ }^{*}[k]+I_{B A T}[k] V_{B A T}[k]}{V_{G}[k]^{2}} p l l[k] .
$$

This current is controlled using a predictive current control with a unipolar PWM modulation strategy. The switching frequency is fixed in $20 \mathrm{kHz}$. The discrete implementation of this current control is defined by:

$$
\begin{aligned}
i_{E V}[k]= & 2 i_{E V}{ }^{*}[k]-i_{E V}{ }^{*}[k-1]-i_{E V \_ \text {error }}[k-1] \\
& -\frac{T}{L}\left(v_{G}[k]-v_{\text {conv }}[k]\right),
\end{aligned}
$$




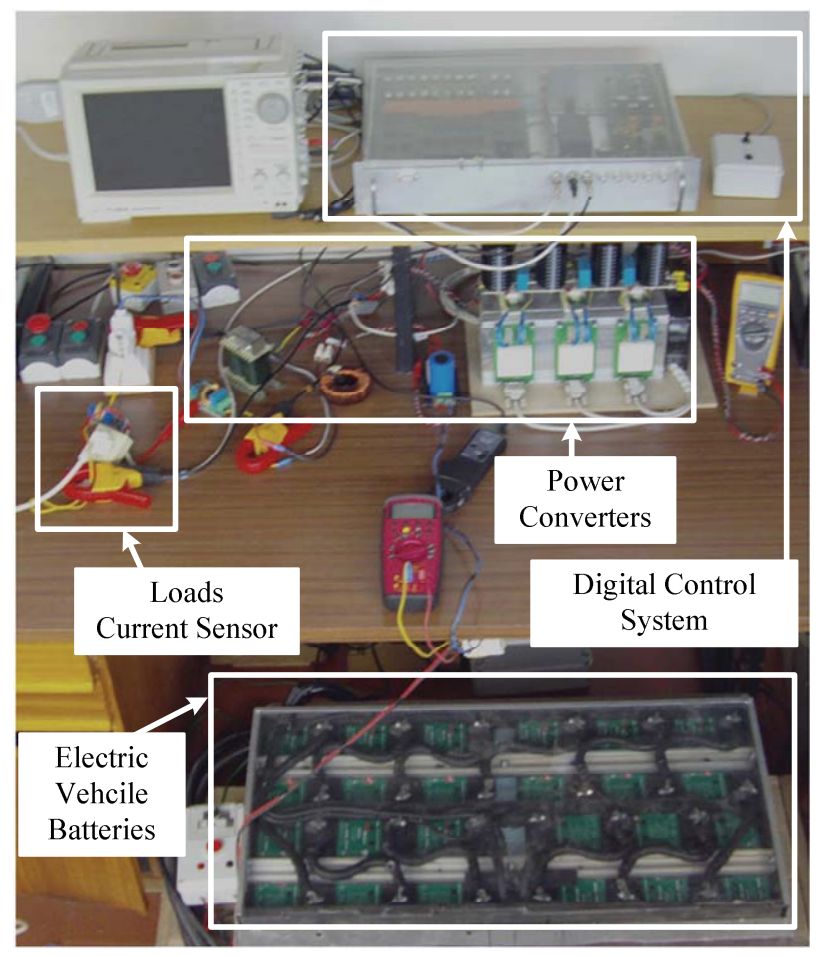

Fig. 7. Laboratory setup used to obtain the experimental results.

where, $v_{\text {conv }}[k]$ denotes the voltage that the ac-dc converter must produce at the instant $[k]$, and $i_{E V_{-} \text {error }}[k-1]$ the current error in the instant $[k-1]$.

\section{EXPERIMENTAL RESULTS}

The proposed EV battery charging strategy was validated under realistic conditions in a laboratory environment. For such purpose was used the aforementioned EV battery charger prototype. Fig. 7 shows the laboratory workbench used to obtain the experimental results, which were obtained with a Yokogawa DL708E digital oscilloscope. Fig. 8 shows the transient response of the EV battery charger current in function of changes in the home loads current, during a period of 50 seconds. In this figure is presented, respectively, the rms values of the total home current $\left(i_{G}\right)$, the loads current $\left(i_{L D}\right)$, and the EV battery charger current $\left(i_{E V}\right)$. As can be seen, the EV battery charger current is adjusted with a smooth response, after a delay needed to update the rms value of the loads current. In this situation the total home current is maintained almost constant and equal to $16 \mathrm{~A}$, while the load current has a maximum variation of $5 \mathrm{~A}$, which corresponds to the same variation in the EV battery charger. Fig. 9 shows the same variables during a period of 10 seconds to illustrate in detail the system response in function of a transient change in the loads current of 7 A. Fig. 10 shows in detail the waveform of the power grid voltage $\left(v_{G}\right)$, the EV battery charger ac current $\left(i_{E V}\right)$, and the EV battery charger dc current $\left(I_{B A T}\right)$ during the battery charging process (G2V operation mode). As shown, although the power grid voltage is slightly distorted, the EV battery charger current is sinusoidal and the power factor is controlled. Taking into account that the battery charger can operate in bidirectional mode, the EV can be used to provide energy to the power grid (V2G operation mode). Fig. 11 shows an example of this situation.

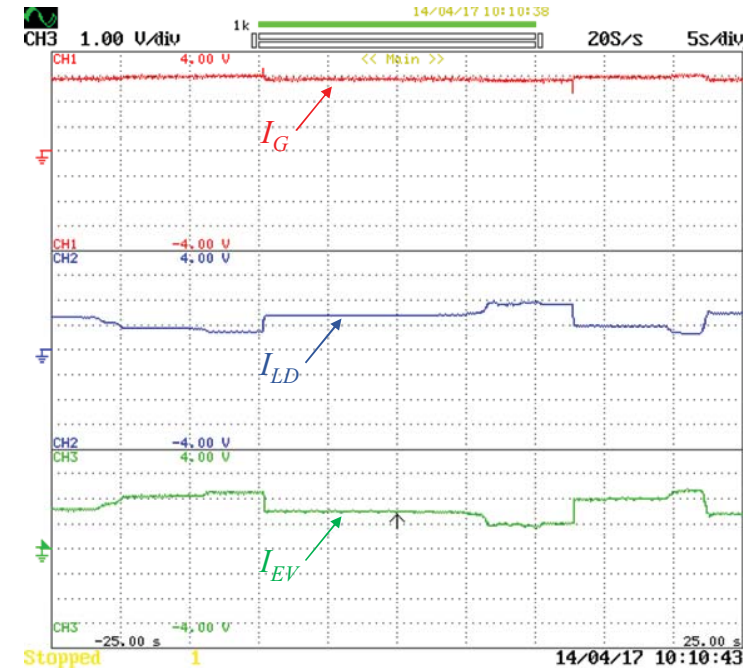

Fig. 8. Total home current $\left(i_{G}\right)$, loads current $\left(i_{L D}\right)$, and EV battery charger current $\left(i_{E V}\right)$ during a transient response $(50 \mathrm{~s})$ to a change in the loads current (5 A / div).

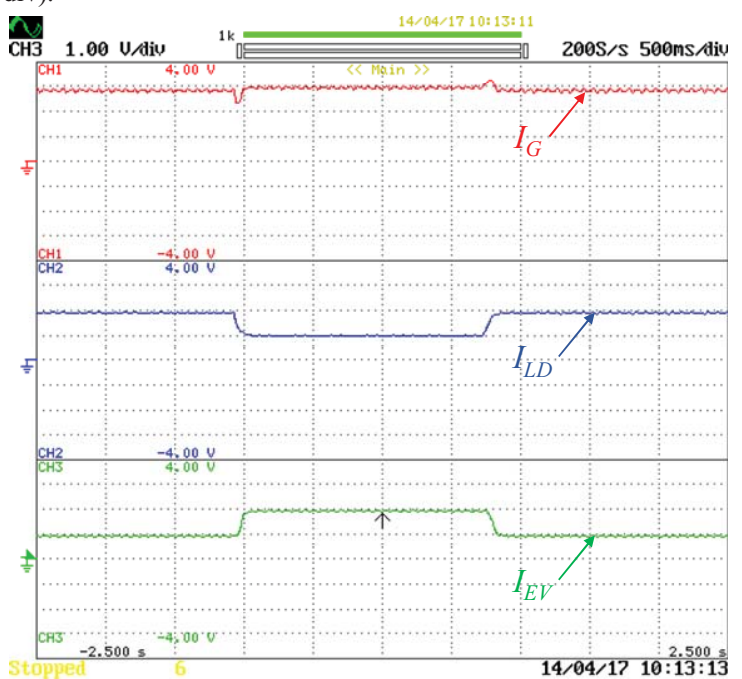

Fig. 9. Detail of the the total home current $\left(i_{G}\right)$, loads current $\left(i_{L D}\right)$, and EV battery charger current $\left(i_{E V}\right)$ during a transient response $(5 \mathrm{~s})$ to a sudden change of $5 \mathrm{~A}$ in the loads current $(5 \mathrm{~A} / \mathrm{div})$.

\section{CONCLUSIONS}

This paper proposes an Electric Vehicle (EV) smart battery charging strategy for targeting the future smart grids. Nowadays, the EV is plugged to the home to perform the battery charging process without any concern about the contracted power for the home. Therefore, it is predictable that will occur overcurrent and the main switch breaker will be tripped. The strategy proposed in this paper consists in regulating the $\mathrm{EV}$ battery charging current in function of the home current. In order to evaluate the proposed strategy it was adapted a bidirectional battery charger prototype to operate in accordance with the required algorithm. The experimental results, obtained both in steady and transient states, show that the EV battery charger prototype with the proposed strategy operates correctly, even under heavy load variations. The results also show that it is possible to perform a superior EV charging management so that the contracted power is never exceeded. 


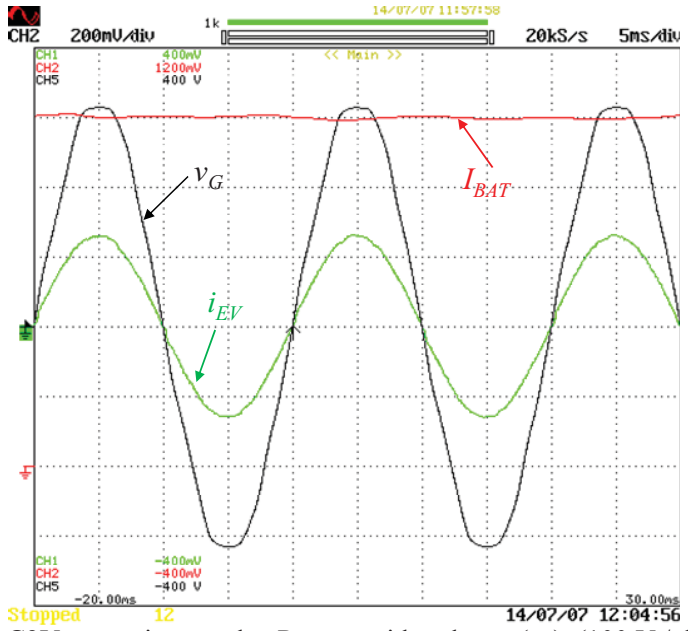

Fig. 10. G2V operation mode: Power grid voltage $\left(v_{G}\right)(100 \mathrm{~V} /$ div $)$; EV battery charger ac current $\left(i_{E V}\right)(10 \mathrm{~A} / \mathrm{div})$; EV battery charger dc current $\left(I_{B A T}\right)(2 \mathrm{~A} / \mathrm{div})$

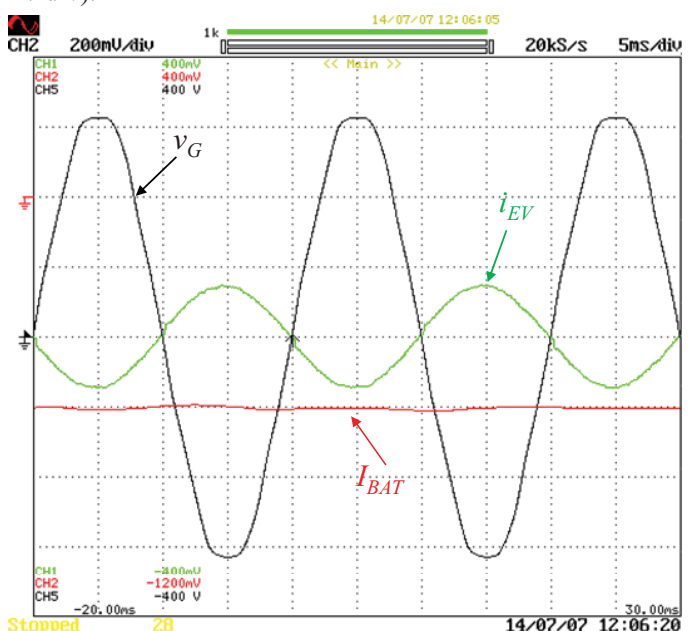

Fig. 11. V2G operation mode: Power grid voltage $\left(v_{G}\right)(100 \mathrm{~V} / \mathrm{div})$; EV battery charger ac current $\left(i_{E V}\right)(10 \mathrm{~A} / \mathrm{div})$; EV battery charger dc current $\left(I_{B A T}\right)(2 \mathrm{~A} / \mathrm{div})$

\section{ACKNOWLEDGMENT}

This work has been supported by FCT - Fundacao para a Ciencia e Tecnologia within the Project Scope: PEst OE/EEI/UI0319/2014. Mr. Vítor Monteiro was supported by the doctoral scholarship SFRH/BD/80155/2011 granted by the FCT agency.

\section{REFERENCES}

[1] Thomas A. Becker, Ikhlaq Sidhu, Burghardt Tenderich, "Electric Vehicles in the United States A New Model with Forecasts to 2030," University of California, Berkeley, Center for Entrepreneurship \& Technology (CET), v.2.0, Aug. 2009.

[2] C.C.Chan, "The State of the Art of Electric, Hybrid, and Fuel Cell Vehicles," Proc. IEEE, vol.95, no.4, pp.704-718, Apr. 2007.

[3] C. C. Chan, Alain Bouscayrol, Keyu Chen, "Electric, Hybrid, and FuelCell Vehicles: Architectures and Modeling," IEEE Trans. Veh. Technol., vol.59, no.52, pp.589-598, Fev. 2010.

[4] "Environmental Assessment of Plug-In Hybrid Electric Vehicles," Electric Power Research Institute and Natural Resources Defense Council, Volume 1: Nationwide Greenhouse Gas Emissions, July 2007.

[5] Ahmed Yousuf Saber, Ganesh Kumar Venayagamoorthy, "Plug-in Vehicles and Renewable Energy Sources for Cost and Emission Reductions," IEEE Trans. Ind. Electron., vol.58, no.4, pp.1229-1238,
Apr. 2011.

[6] Rui Freire, Joaquim Delgado, João M. Santos, Aníbal T. de Almeida, "Integration of Renewable Energy Generation with EV Charging Strategies to Optimize Grid Load Balancing," IEEE Conference on Intelligent Transportation Systems, pp.392-396, Sept. 2010.

[7] Willet Kempton, Victor Udo, Ken Huber, Kevin Komara, Steve Letendre, Scott Baker, Doug Brunner, Nat Pearre, "A test of vehicle-togrid (V2G) for energy storage and frequency regulation in the PJM system," University of Delaware, Nov. 2008.

[8] Sekyung Han, Soohee Han, Kaoru Sezaki, "Development of an Optimal Vehicle-to-Grid Aggregator for Frequency Regulation," IEEE Trans. Smart Grid, vol.1, no.1, pp.65-72, June 2010.

[9] Vítor Monteiro, J. G. Pinto, Bruno Exposto, João C. Ferreira, Carlos Couto, João L. Afonso, "Assessment of a Battery Charger for Electric Vehicles with Reactive Power Control," IEEE IECON Industrial Electronics Society, Montréal-Canada, pp.5124-5129, Oct. 2012.

[10] J. G. Pinto, Vítor Monteiro, Henrique Gonçalves, Bruno Exposto, Delfim Pedrosa, Carlos Couto, João L. Afonso, "Bidirectional Battery Charger with Grid-to-Vehicle, Vehicle-to-Grid and Vehicle-to-Home Technologies," IEEE IECON Industrial Electronics Conference, pp.5934-5939, Vienna Austria, Nov. 2013

[11] Vítor Monteiro, Henrique Gonçalves, João L. Afonso, "Impact of Electric Vehicles on Power Quality in a Smart Grid Context," IEEE EPQU International Conference on Electrical Power Quality and Utilisation, pp.1-6, Oct. 2011.

[12] João A. Peças Lopes, Filipe Soares, Pedro M. Rocha Almeida, "Integration of Electric Vehicles in the Electric Power Systems," Proc. IEEE, vol.99, no.1, pp.168-183, Jan. 2011.

[13] João C. Ferreira, Vítor Monteiro, João L. Afonso, A. Silva, "Smart Electric Vehicle Charging System," IEEE IVS 4th International IEEE Intelligent Vehicles Symposium, Baden-Baden Germany, pp.758 763, June 2011.

[14] Yonghua Song, Xia Yang, Zongxiang Lu, "Integration of Plug-in Hybrid and Electric Vehicles Experience from China," IEEE PES Power and Energy Society General Meeting, pp.1-6, July 2010.

[15] G. Joos, M. R. Dubois, "Integration of PHEVs and EVs Experience from Canada," IEEE PES Power and Energy Society General Meeting, pp.15, July 2010.

[16] Paul S. Moses, Sara Deilami, Amir S. Masoum, Mohammad A. S. Masoum, "Power Quality of Smart Grids with Plug-in Electric Vehicles Considering Battery Charging Profile," IEEE Innovative Smart Grid Technologies Conference Europe, pp.1-7, Oct. 2010.

[17] Fariborz Musavi, Murray Edington, Wilson Eberle, William G. Dunford, "Evaluation and Efficiency Comparison of Front End AC-DC Plug-in Hybrid Charger Topologies," IEEE Trans. Smart Grid, vol.3, no.1, pp.413-421, Mar. 2012.

[18] Trevor Morgan, "Smart Grids and Electric Vehicles: Made for Each Other?," International Transport Forum, Discussion Paper, Fev. 2012

[19] Ho-Sung Kim, Myung-Hyo Ryu, Ju-Won Baek, Jee-Hoon Jung, "HighEfficiency Isolated Bidirectional AC-DC Converter for a DC Distribution System," IEEE Trans. Power Electron., vol.28, no.4, pp.1642-1654, Apr. 2013.

[20] Vehbi C. Gungor, Dilan Sahin, Taskin Kocak, Salih Ergut, Concettina Buccella, Carlo Cecati, Gerhard P. Hancke, "Smart Grid and Smart Homes - Key Players and Pilot Projects," IEEE Ind. Electron. Mag., vol.6, pp.18-34, Dec. 2012.

[21] Nobuo Saito, "Ecological Home Network: An Overview," Proc. IEEE, vol.101, no.11, pp.2428-2435, Nov. 2013.

[22] J. Martins, F. P. Brito, D. Pedrosa, Vítor Monteiro, João L. Afonso, "Real-Life Comparison between Diesel and Electric Car Energy Consumption," in Grid Electrified Vehicles: Performance, Design and Environmental Impacts, 1st ed., Carla Alexandra Monteiro da Silva, Ed. Nova Science Publishers, 2013, Chapter 10, pp.209-232.

[23] M. Karimi-Ghartemani, M. R. Iravani, “A nonlinear adaptive filter for online signal analysis in power systems: applications," IEEE Trans. Power Del., vol.17, no.2, pp.617-622, Apr. 2002. 